\title{
Optimal Reactive Extraction of Valeric Acid from Aqueous Solutions Using Tri-n-propyl amine/Diluent and Dibenzyl amine/Diluent Systems
}

\author{
A. Senol, ${ }^{*}$ M. Bilgin, B. Baslioglu \\ Department of Chemical Engineering, \\ Faculty of Engineering, Istanbul University, \\ 34320 Avcilar, Istanbul, Turkey
}

doi: 10.15255/CABEQ.2015.2223

Original scientific paper

Received: April 29, 2015

Accepted: August 31, 2016

\begin{abstract}
Reactive extraction of valeric acid from water by tri- $n$-propyl amine (TPA) and dibenzyl amine (DBA) dissolved in polar oxygenated aliphatic diluents (diethyl sebacate, diethyl succinate, diethyl malonate, ethyl caprylate, ethyl valerate and isoamyl alcohol) has been studied at $T=298 \pm 0.2 \mathrm{~K}$ and $P=101.3 \pm 0.7 \mathrm{kPa}$. Distribution data have been subjected to formulation of an optimization structure for effective acid separation. The optimization approach uses separation ratio $R$ and synergistic enhancement $S E$ factors to efficiently identify optimum extraction ranges. Among the examined aliphatic ester and alcohol diluents, monoesters exhibit higher solvation efficiency comprising acid amine $_{1}$ complex formation, while isoamyl alcohol yields larger loading factors. The uptake capacity of the amine/diluent system is ranging in the order TPA $>$ DBA.

Modeling efforts based on the mass-action law principles have shown considerable success. The mass action law chemodel and modified Langmuir approach are quite accurate yielding mean errors of $0.9 \%$ and $0.7 \%$, respectively.
\end{abstract}

Key words:

extraction, valeric acid, amine, modeling, optimization

\section{Introduction}

Long-chain saturated aliphatic tertiary amines (e.g., Alamine 336; 308) dissolved in protic, non-protic, and polar diluents are effective extractants for carboxylic acids. ${ }^{1-14}$ The amine extractants have been widely used for the extractive recovery of carboxylic acids from aqueous solutions, such as fermentation broth and wastewater including lower than $10 \%(\mathrm{w} / \mathrm{w})$ acid content. ${ }^{1-8}$ The experimental findings of King and co-workers ${ }^{1-3}$ and Senol and co-workers ${ }^{7-14}$ have revealed that the characterization of acid-amine complexation is intimately connected to the polarity and hydrogen bonding affinity of diluent. Three major factors have been found to influence the equilibrium characteristics of amine extraction of carboxylic acids from aqueous solutions, i.e., the nature of acid, concentrations of the acid and extractant, and the type of diluent. ${ }^{1-14} \mathrm{Si}-$ multaneously, the influence of additional controlling factors, such as temperature, $\mathrm{pH}$, swing effect of a mixed diluent and a third phase formation can also modify the reversible complexation stage..$^{15}$ The implementation of amine extraction method argues an uncoupling of the behaviors relative to the diluent/ complex interaction from the physical solubility of the acid to establish a sentence structure distinguishing the dominating factors of extraction. In-

"Corresponding author (A. Senol), E mail: asenol@istanbul.edu.tr, Fax: 902124737180 herent to this uncoupling, the complementary solvation effect of an oxygen-containing, substituted aromatic or aliphatic diluent is considered to be an important complexation factor. ${ }^{1-14}$ However, the experimental findings of Yang et $a l^{4}{ }^{4}$ and Senol et al. ${ }^{7-14}$ give evidence for the reversible complexation between the tertiary amine and the non-dissociated part of the acid in the organic phase being overly sensitive to the solvation efficiency of diluent. The extraction power of an amine/diluent system has been found to decrease in the order: valeric acid $>$ butyric acid $>$ propionic acid $>$ levulinic acid $>$ acetic acid $>$ formic acid. . $^{4-14}$

Comprehensive studies of reactive extraction systems covering diluents from protic, non-protic, polar, and inert classes reveal that the stoichiometry of the acid-amine complexes is intimately connected to the strength of the complex solvation by the diluent increasing in the order: aliphatic hydrocarbon $<$ alkyl aromatic $<$ halogenated aromatic $<$ ketone $<$ proton-donating halogenated aliphatic hydrocarbon $<$ nitrobenzene $<$ alcohols. ${ }^{1-18}$ The effect of diluent is mainly focused on its ability to solvate polar ionpair organic species through dipole-dipole interaction or hydrogen bonding, favoring the formation of one or simultaneously at least two acid-carrier complexes. ${ }^{2-14}$ The experimental findings manifest the fact that a polar diluent is capable of increasing the extracting power of non-polar amines by providing additional solvating power that allows higher 
levels of polar acid-amine complexes to stay in the organic phase..$^{2-5,7-14}$

Distribution of valeric acid between water and basic amine extractants tri- $n$-propyl amine (TPA) and dibenzyl amine (DBA) dissolved in polar oxygenated aliphatic diluents, as well as the extraction capacity of pure diluent alone have been studied at isothermal conditions $(T=298 \pm 0.2 \mathrm{~K})$. This article will also discuss the effect of the solvent structure on the extraction power of amine/diluent system, as well as the competition between physical extraction and chemical interaction regarding the behavior of both protic and non-protic polar aliphatic solvents, diethyl sebacate, diethyl succinate, diethyl malonate, ethyl caprylate, ethyl valerate, and isoamyl alcohol. Experimental data for the present systems of TPA/diluent/valeric acid and DBA/diluent/valeric acid are not available in the open literature.

It may be desirable to use a high-boiling amine-reactive extractant that does not have to be distilled so long as no azeotropes appear. Regarding the technical and economic merits of high-boiling amine extractants during the regeneration by distillation, the selection of TPA $\left(T_{\mathrm{b}}=429 \mathrm{~K}\right)$ and DBA $\left(T_{\mathrm{b}}=573 \mathrm{~K}\right)$ of higher boiling temperatures than water $\left(T_{\mathrm{b}}=373 \mathrm{~K}\right)$ was made. In addition, four selected non-protic oxygen-containing diluents - diethyl sebacate $\left(T_{\mathrm{b}}=585 \mathrm{~K}\right)$, diethyl succinate $\left(T_{\mathrm{b}}=\right.$ $491 \mathrm{~K})$, diethyl malonate $\left(T_{\mathrm{b}}=472 \mathrm{~K}\right)$ and ethyl caprylate $\left(T_{\mathrm{b}}=480 \mathrm{~K}\right)$ have higher boiling temperatures than valeric acid $\left(T_{\mathrm{b}}=461.5 \mathrm{~K}\right)$ and water, whereas the polar ethyl valerate $\left(T_{\mathrm{b}}=418 \mathrm{~K}\right)$ and isoamyl alcohol $\left(T_{\mathrm{b}}=403 \mathrm{~K}\right)$ diluents have higher vapor pressures than valeric acid. In particular, solvents used in the present extraction systems should be of low cost, low toxicity, and rather high boiling temperature properties, while their viscosities and densities should be close to those of water. However, they should give proper liquid-liquid equilibrium (LLE) data for the excellent design and productive operation of the related extraction equipment.

As a continuation of the previous study ${ }^{7-14}$, the present work aims to generate new LLE data for the reactive extraction of valeric acid from water at $T=298 \pm 0.2 \mathrm{~K}$ and $P=101.3 \pm 0.7 \mathrm{kPa} \quad$ using TPA/diluent and DBA/diluent solvent systems of lower vapor pressure (higher boiling temperature) than water. No dependable results were found in the literature for the studied extractants and diluents applied to the valeric acid extraction. It is, therefore, of interest to extend the previous works to accommodate the additional data on the amine extraction of valeric acid from the aqueous solution and to model analytically the properties of relevant reactive extraction systems. Due to the synergistic effect of physical extraction and chemical interaction,
TPA/diluent and DBA/diluent solvent systems can improve the extraction efficiency of the considered hydrophobic acid. The distribution data have been used to develop an equilibrium model for reactive extraction of valeric acid. However, this study also deals with a new conceptual definition for optimum extraction as the locus of the proposed separation factors being used as the optimization criteria for the considered reactive extraction system. The optimization problem is solved both graphically and analytically along with considering a non-homogeneous differential equation to represent conformably the non-linear variation profile of the optimized quantity. In order to accomplish this task, the derivative variation method has been applied to identifying the optimization range.

The possibility of achieving a synergism by a solvent mixture composed mainly of a commercial amine and a conventional diluent has led to extensive research over optimum recovery of valeric acid from aqueous solutions depending on various factors like the types and concentrations of amine, diluent and acid, temperature, etc. ${ }^{19,20}$ It can be observed from the experimental results, reported by Luque et $a l .{ }^{19}$ and $\mathrm{Senol}^{20}$ for amine extraction of valeric acid by commercial extractants Amberlite LA-2/toluene and Alamine 336/diluent, that the effect of temperature and aqueous-phase acid concentration on the phase equilibrium should be accustomed to a regularly small change in separation efficiency of amine because of a limited acid solubility in water, therefore, the extraction at different temperatures and aqueous acid concentrations has not been studied here.

The properties of amine/diluent/valeric acid system of hydrogen-bond formation can be estimated through theoretically-based models depending on the mass action law methodology ${ }^{14,21}$ and linear solvation energy relation (LSER) principles. ${ }^{22,23} \mathrm{Ex}-$ tensions to these models for predicting the phase behavior of reactive extraction systems containing especially amine/polar or non-polar diluent/monocarboxylic acid have expanded the model's versatility. ${ }^{8,11,12,19,20}$ In this study, the results were correlated in terms of a chemodel and a modified Langmuir model, and checked for consistency in reproducing the observed optimization quantity.

\section{Theoretical}

\section{Criteria of extraction efficiency}

The results were interpreted in terms of the distribution ratio $D$, the degree of extraction $E$, the overall loading factor of the amine $Z$, the stoichiometric loading factor $Z_{s}$ and the chemical separation factor $s_{\mathrm{f}}^{\text {chem }}$ representing the acid separation due to a 
chemical interaction. ${ }^{7-14}$ We also introduce here the physical separation factor $s_{\mathrm{f}}^{\text {phys }}$ to characterize the degree of physical extraction. Additionally, two new factors including both chemical $\left(s_{\mathrm{f}}^{\text {chem }}\right)$ and physical $\left(s_{\mathrm{f}}^{\text {phys }}\right)$ interaction terms are used to account for the optimum amine extraction of valeric acid, namely, the separation ratio optimization factor $R$ and the synergistic enhancement factor $S E$.

$D$ and $E$ factors, defined by eqs. (1a) and (1b), respectively, are widely used for representing the effectiveness of an extraction process. The overall loading factor $Z_{\mathrm{t}}$ is the ratio of total amount of acid extracted $\bar{C}_{\mathrm{TA}}$ to the initial organic phase concentration of the amine (AM) $\overline{C_{\mathrm{AM}}^{0}}$, eq. (1c). The stoichiometric loading factor $Z_{\mathrm{s}}$ is the ratio of the overall complexed acid in the organic phase to the initial amount of the amine, eq. (1d). This factor includes a correction term $\left(v C_{\mathrm{TA}}^{\mathrm{d}}\right)$ for the amount of acid extracted by the diluent in the solvent mixture. The chemical separation factor $S_{\mathrm{f}}^{\text {chem }}$ stands for the ratio of the complexed acid with the extractant $\overline{C_{\mathrm{HA}}}$ to the overall extracted acid in the organic phase $\overline{C_{\mathrm{TA}}}$, eq. (1e). As reciprocal of $s_{\mathrm{F}}^{\mathrm{chem}}$, the physical separation factor $s_{\mathrm{f}}^{\text {phys }}$ accounts for the degree of physically extracted acid portion by the diluent, eq. (1f). A relative proportion between chemical and physical interactions is evaluated in terms of the separation ratio optimization factor $R$, eq. $(1 \mathrm{~g})$. For an equivalent contribution of both physical and chemical interactions, $R=1$. The synergistic enhancement factor $S E$, eq. (1h), is a measure of the synergistic extraction power of amine/diluent system.

$$
\begin{gathered}
D=\overline{C_{\mathrm{TA}}} / C_{\mathrm{TA}} \\
E=100\left(\overline{C_{\mathrm{TA}}} / C_{\mathrm{TA}}^{0}\right)=100\left(1-\frac{C_{\mathrm{TA}}}{\mathrm{C}_{\mathrm{TA}}^{0}}\right)(\%) \\
Z_{\mathrm{t}}=\overline{C_{\mathrm{TA}}} / \overline{C_{\mathrm{AM}}^{0}} \\
Z_{\mathrm{s}}=\frac{\overline{C_{\mathrm{TA}}}-\bar{v} \overline{C_{\mathrm{TA}}^{\mathrm{d}}}}{\overline{C_{\mathrm{AM}}^{0}}}=\frac{\overline{C_{\mathrm{HA}}}}{\overline{C_{\mathrm{AM}}^{0}}} \\
s_{\mathrm{f}}^{\text {chem }}=\overline{C_{\mathrm{HA}}} / \overline{C_{\mathrm{TA}}} \\
s_{\mathrm{f}}^{\text {phys }}=1-s_{\mathrm{f}}^{\text {chem }} \\
R=\frac{s_{\mathrm{f}}^{\text {chem }}}{s_{\mathrm{f}}^{\text {phys }}} \\
S E=\frac{1}{S_{\mathrm{f}}^{\text {chem }}}+\frac{1}{S_{\mathrm{f}}^{\text {phys }}}
\end{gathered}
$$

where $v$ and $\overline{C_{\mathrm{TA}}^{\mathrm{d}}}$ designate the volume fraction of diluent in the solvent mixture and the amount of acid extracted by the pure (amine-free) diluent alone, respectively. $\overline{C_{\mathrm{AM}}^{0}}$ and $\overline{C_{\mathrm{TA}}^{0}}$ stand for the initial concentrations of the extractant and acid, respectively. $\bar{C}_{\mathrm{HA}}, \bar{C}_{\mathrm{TA}}$ and $C_{\mathrm{TA}}$ represent the concentrations of the complexed acid, the overall extracted acid by the amine/diluent system and the aqueous phase acid content, respectively. Concentrations are given in $\left(\mathrm{mol} \mathrm{dm}^{-3}\right)$ unit. The species in the organic phase are presented by the overbar.

Traditionally, $D$ and $E$ account for the distribution effect of acid, whereas $Z_{\mathrm{t}}$ is a measure of the effectiveness with which the amine loading is contributed to the acid extraction. $s_{\mathrm{f}}^{\text {chem }}$ and $s_{\mathrm{f}}^{\text {phys }}$ factors are fair measures of relative contribution of chemical and physical interactions to the overall extraction process, respectively. The competition between chemical interaction and physical extraction is quantitatively measured by $R$, while $S E$ fairly accounts for the effectiveness with which valeric acid can be synergistically extracted by amine/diluent system. Firmly, $D, E$ and $Z_{\mathrm{t}}$ are essential in evaluating the phase behavior of a reactive extraction system, but they are not exactly sufficient for the description of the physical event. Here, $Z_{\mathrm{s}}$ somewhat gives evidence for a probable stoichiometry (or degree) of chemical aggregation between acid and amine, while $s_{\mathrm{f}}^{\text {chem }}$ characterizes quantitatively whether the chemical association is formally dominated over physical interaction or not. Whereas $R$ and $S E$ are originally intended for the description of the optimum extraction field of relevant systems. In general, the examined optimization structure using $R$ and $S E$ gives a realistic picture of whether an optimum point exists and how its values can be determined, and this process brings a new perspective to literature. Although $R$ and $S E$ are about equally strongly dependent on $S_{\mathrm{f}}^{\mathrm{chem}}$, they exhibit opposite variation profiles and different curve slopes with an increase in amine concentration, so that the relative proportion between chemical and physical interactions and the degree of synergism can be quantified and thus independently applied to the estimation of optimum conditions. The present study differs from the literature works, as it investigates and compares special amine extractants and ester diluents simultaneously on an efficiency-basis using eight extraction factors, which imperatively take a role in the description of phase behavior of a complex reactive extraction system composed of (tertiary or secondary amine/monobasic ester or dibasic ester or alcohol/valeric acid). This is a stringent test of the suitability of TPA/diluent and DBA/diluent systems for reactive extraction of valeric acid, and the applicability of the proposed optimization structure to the description of optimum extraction field in terms of the above-mentioned factors. 


\section{Equilibrium models of mass action law}

Using the chemical modeling concepts of mass action law $^{7-14}$, the overall extraction equilibrium of valeric acid/TPA/diluent and valeric acid/DBA/diluent systems can be described by a complex formation through the interfacial reaction, eq. (2). The conditioned extraction constant $\beta_{p q}$ including the activity coefficients of species is defined in the molarity scale $\left.(\mathrm{mol} \mathrm{dm})^{-3}\right)^{1-p-q}$ by eq. (3):

$$
\begin{gathered}
p \mathrm{HA}+q \overline{\mathrm{NR}_{3}}=\overline{(\mathrm{HA})_{p}\left(\mathrm{NR}_{3}\right)_{q}}, \\
p=1, k ; q=1, l \\
p \mathrm{HA}+q \overline{\mathrm{NR}_{2} \mathrm{H}}=\overline{(\mathrm{HA})_{p}\left(\mathrm{NR}_{2} \mathrm{H}\right)_{q}}, \\
p=1, k ; q=1, l \\
\beta_{p q}=\overline{C_{p q}} /\left(C_{\mathrm{HA}}{ }^{p} \overline{C_{\mathrm{AM}}}{ }^{q}\right), p=1, k ; q=1, l
\end{gathered}
$$

where $\mathrm{HA}, \overline{\mathrm{NR}_{3}}$ and $\overline{\mathrm{NR}_{2} \mathrm{H}}$ represent the non-dissociated acid in the aqueous phase, tri- $n$-propyl amine (TPA) and dibenzyl amine (DBA), respectively. $\overline{(\mathrm{HA})_{p}\left(\mathrm{NR}_{3}\right)_{q}}$ and $\overline{(\mathrm{HA})_{p}\left(\mathrm{NR}_{2} \mathrm{H}\right)_{q}}$ stand for the acid-amine complexes. The overbar denotes species in the organic phase. $C_{\mathrm{HA}}, \overline{C_{\mathrm{AM}}}$ and $\overline{C_{p q}}$ designate the equilibrium concentrations of non-dissociated acid in the aqueous phase, non-complexed amine and acid-amine $(p, q)$ complex, respectively. The total equilibrium content of complexed acid $\left(\overline{C_{\mathrm{HA}}}\right)$, is the sum of contributions of the individual complexes defined by eq. (4).

$$
\overline{C_{\mathrm{HA}}}=\sum_{p=1}^{k} \sum_{q=1}^{l} p \beta_{p q} C_{\mathrm{HA}}{ }^{p} \overline{C_{\mathrm{AM}}}{ }^{q}
$$

By incorporating eq. (4) into the overall balance equation for acid, the equilibrium model is derived, eq. (5), along with considering equal volumes of organic and aqueous phases.

$$
C_{\mathrm{TA}}^{0}=\overline{C_{\mathrm{d}}}+\overline{C_{\mathrm{HA}}}+C_{\mathrm{TA}}
$$

where $C_{\mathrm{TA}}^{0}, C_{\mathrm{TA}}$ and $\overline{C_{\mathrm{d}}}$ stand for the initial and total aqueous phase acid concentrations, and concentration related to the acid portion physically extracted by the diluent in the solvent mixture, respectively. The non-dissociated aqueous phase acid concentration $C_{\mathrm{HA}}$ is to be calculated from $C_{\mathrm{TA}}, \mathrm{pH}$ and the dissociation constant of valeric acid $(K)$ in the aqueous phase due to eq. (6) using $\mathrm{p} K_{a}=4.842$ for valeric acid. ${ }^{24} C_{\mathrm{H}^{+}}$is the molar aqueous-phase concentration of proton.

$$
C_{\mathrm{HA}}=C_{\mathrm{TA}} C_{\mathrm{H}^{+}} /\left(C_{\mathrm{H}^{+}}+K_{a}\right)
$$

Interpretation of the equilibrium results relative to amine-based reactive extraction systems has revealed that all possible acid-carrier $(p, q)$ combina- tions for $p=1-k$ and $q=1-l$ should not require to be explicitly evaluated. ${ }^{7-14}$ In the prediction of equilibrium, different sets of an appropriate acid-amine aggregation have been selected for valeric acid, regarding the overall loading region and the maximum loading values, i.e. the plateau of the loading curve. Accordingly, aggregation of simple complexes into larger adducts has been assumed.

The equilibrium data for the reactive extraction of valeric acid can be interpreted in terms of the mass action law chemodel given by eq. (7) associated with eqs. (4) and (5) to achieve a model structure involving $Z_{\mathrm{t}}, C_{\mathrm{HA}}$ and $C_{\mathrm{TA}}^{0}$ quantities.

$$
\begin{aligned}
& Z_{\mathrm{t}}= \frac{\overline{C_{\mathrm{d}}}+\overline{C_{\mathrm{HA}}}}{\overline{C_{\mathrm{AM}}^{0}}}=\frac{v D_{0} C_{\mathrm{TA}}^{0}}{\left(1+D_{0}\right) \overline{C_{\mathrm{AM}}^{0}}}+ \\
&+\frac{\sum_{p=1}^{k} \sum_{q=1}^{l} p \beta_{p q} C_{\mathrm{HA}} \bar{C}^{q} \overline{\mathrm{AM}}^{q}}{\overline{C_{\mathrm{AM}}^{0}}}
\end{aligned}
$$

where $\overline{C_{\mathrm{d}}}=v D_{0} C_{\mathrm{TA}}^{0} /\left(1+D_{0}\right)$ represents the concentration of the physically extracted acid part by the diluent. $D_{0}$ is the distribution ratio of the acid referred to the diluent alone. The adjustable extraction constant $\beta_{p q}$ for the relevant system has been regressed due to eq. (7) supposing one or two $(p, q)$ acid $_{p}-$ amine $_{q}$ complex formation.

In a similar way, the Langmuir equilibrium model of Bauer et al. ${ }^{25}$ has been applied to relevant extraction systems along with considering an overall acid-extractant complexation with an associated number $(z)$ relative to the maximum loading of the extractant, $z=Z_{\mathrm{s}, \max }$. By incorporating $\overline{C_{\mathrm{HA}}}$ from the Bauer model to the $Z_{\mathrm{t}}$ factor, a unified model structure eq. (8) is derived involving both physical and chemical interaction terms.

$$
Z_{\mathrm{t}}=\frac{\overline{C_{\mathrm{d}}}+\overline{C_{\mathrm{HA}}}}{\overline{C_{\mathrm{AM}}^{0}}}=\frac{v D_{0} C_{\mathrm{TA}}^{0}}{\left(1+D_{0}\right) \overline{C_{\mathrm{AM}}^{0}}}+\frac{z \beta_{\mathrm{L}} C_{\mathrm{HA}}{ }^{z}}{1+\beta_{\mathrm{L}} C_{\mathrm{HA}}{ }^{z}}
$$

where $\overline{C_{\mathrm{d}}}, D_{0}, \overline{C_{\mathrm{AM}}^{0}}, C_{\mathrm{TA}}^{0}$ and $C_{\mathrm{HA}}$ stand for the same quantities as defined by eq. (7). The Langmuir extraction constant $\beta_{\mathrm{L}}$ in $\left.(\mathrm{mol} \mathrm{dm})^{-3}\right)^{-z}$ is attributed to the overall reaction eq. $(2 \mathrm{a})$ or $(2 \mathrm{~b})$, supposing the formation of only one type $(p / q=z)$ of aggregated structure. The assumption inherent in this approach is attributed to an associated number of acid-amine complexation related to the maximum loading $z=Z_{\mathrm{s}, \max }=\left(\overline{C_{\mathrm{HA}}}\right)_{\max } / \overline{C_{\mathrm{AM}}^{0}}$.

\section{Experimental}

Valeric acid ( $99 \%, \mathrm{GC})$, as well as the reactive extractants tri- $n$-propyl amine TPA (98\%) and dibenzyl amine DBA (98\%), and six organic sol- 
vents - diethyl sebacate (98\%), diethyl succinate (>98\%), diethyl malonate (99\%), ethyl caprylate $(98 \%)$, ethyl valerate $(>98 \%)$, and isoamyl alcohol (99\%) of analytical grade purity were furnished by Merck and Aldrich. All the chemicals were used as received without further purification. Deionized and redistilled water was used in all experiments.

The extraction experiments were performed using an equilibrium glass cell equipped with a magnetic stirrer and thermostatted at $T=298 \pm 0.2 \mathrm{~K}^{26}$ Equal volumes $\left(10 \mathrm{~cm}^{3}\right)$ of initial aqueous valeric acid and organic (TPA/diluent or DBA/diluent) phases were agitated for $1 \mathrm{~h}$ and then left for $2 \mathrm{~h}$ to settle down into aqueous and solvent layers at a fixed temperature $(T=298 \pm 0.2 \mathrm{~K})$ and pressure $(P=101.3 \pm 0.7 \mathrm{kPa}) .{ }^{26}$ The contact time enough to reach equilibrium, and the waiting time required to separate the conjugate phases were determined in preliminary analysis, which were found to be sufficient for a complete extraction. ${ }^{26}$ The effective separation of the phases was ensured by centrifugation. Aqueous-phase $\mathrm{pH}$ was measured using an Orion 601A pH-meter. Aqueous-phase acid concentration was determined by titration with aqueous $\mathrm{NaOH}$ (Titrosol A, Merck) and phenolphthalein indicator, as well as using an UV-spectrophotometer (Perkin Elmer Lambda 35 Model). The organic phase acid concentration was analyzed by Hewlett-Packard GC Analyzer, Model 5890A, equipped with FID and a capillary column, HP1-type $50 \mathrm{~m} \times 0.2 \mathrm{~mm} \times 0.5$ $\mu \mathrm{m}$. Nitrogen was used as a carrier gas at a flow rate of $5 \mathrm{~mL} \mathrm{~min}{ }^{-1}$. The initial amine/diluent content in the organic phase was determined gravimetrically by weighing with a Sartorius scale accurate to within $\pm 10^{-4} \mathrm{~g}$, in addition to chromatographical analysis using Hewlett-Packard GC Analyzer.

The acid analysis was checked by a mass balance. It was confirmed from two independent replicates that the valeric acid extraction experiments were reproducible within at most $3 \%$ standard deviation. ${ }^{26}$ The initial acid content in the aqueous phase was kept at $C_{\mathrm{TA}}^{0}=0.3329 \mathrm{~mol} \mathrm{dm}^{-3}$. To eliminate a third phase formation, the initial amine concentration was restricted in the range of $0.25-1.05 \mathrm{~mol} \mathrm{dm}^{-3}$. Tests covering the influence of the solvent structure and concentration on the extraction degree of valeric acid were performed using protic (isoamyl alcohol), and polar and proton-accepting (diethyl sebacate, diethyl succinate, diethyl malonate, ethyl caprylate, ethyl valerate) oxygenated diluents for two basic amine extractants TPA and DBA. The physical extraction of the acid by the diluent alone was also studied. However, the relative dependence of the extraction efficiency on the structural properties of the carrier and diluent has been elucidated by comparing the extraction capabilities pertaining to TPA and DBA dissolved in the above-mentioned es-
Table 1 - Mutual solubility of binaries ( $w$, water $+w_{2}$, solvent) in terms of mass fraction (w) at $T=298 \mathrm{~K}$ and $P=101.3 \mathrm{kPa}^{a}$

\begin{tabular}{l|c|c|c|c}
\hline \multirow{2}{*}{ Binary system } & \multicolumn{2}{c|}{$\begin{array}{c}\text { Solvent (2) } \\
\text { in water (1) }\end{array}$} & \multicolumn{2}{c}{$\begin{array}{c}\text { Water (1) } \\
\text { in solvent (2) }\end{array}$} \\
\cline { 2 - 6 } & $w_{1}$ & $w_{2}$ & $w_{1}$ & $w_{2}$ \\
\hline Water + diethyl sebacate & 0.9990 & 0.0010 & 0.0019 & 0.9981 \\
Water + diethyl succinate & 0.9981 & 0.0019 & 0.0104 & 0.9896 \\
Water + diethyl malonate & 0.9806 & 0.0194 & 0.0200 & 0.9800 \\
Water + ethyl caprylate & 0.9979 & 0.0021 & 0.0036 & 0.9964 \\
Water + ethyl valerate & 0.9942 & 0.0058 & 0.0082 & 0.9918 \\
Water + isoamyl alcohol & 0.9784 & 0.0216 & 0.1030 & 0.8970 \\
Water + tri- $n$-propyl amine & 0.99927 & 0.00073 & 0.00061 & 0.99939 \\
Water + dibenzyl amine & 0.99990 & 0.00010 & 0.00014 & 0.99986 \\
\hline
\end{tabular}

a Standard uncertainties $u$ are $u(T)=0.2 \mathrm{~K}, u(P)=0.7 \mathrm{kPa}$, $u(w)=0.002$.

ter and alcohol diluents for the identical experimental conditions at $\mathrm{A}: \mathrm{O}=1: 1(\mathrm{v} / \mathrm{v}), T=298 \pm 0.2 \mathrm{~K}$, $P=101.3 \pm 0.7 \mathrm{kPa}$ and the initial aqueous acid solution of $C_{\mathrm{TA}}^{0}=0.3329 \mathrm{~mol} \mathrm{dm}^{-3}$ used as a simulated synthetic fermentation sample. The solubilities of the extractant, diluent and organic complex in the aqueous phase are negligible in the range of the variables investigated. Similarly, the change in the phase volume was neglected. This is confirmed by the experimental results in Table 1 for the mutual solubility of (water + solvent) binaries obtained by the cloud point method. ${ }^{26,27}$

As reported by Luque et al. ${ }^{19}$ and $\mathrm{Senol}^{20}$, the variation of temperature or aqueous-phase acid concentration can produce a slight effect on removal efficiency of valeric acid by commercial amine extractants (Amberlite LA-2, Alamine 336), therefore, the extraction equilibrium at different temperatures and aqueous acid concentrations will be accordingly considered redundant and not studied here.

\section{Results and discussion}

\section{Factors affecting the extraction power of TPA and DBA}

The equilibrium results for the extraction of valeric acid by pure diluent alone and amine/diluent mixture are provided in Table 2 and Figs. 1-4. Study of the extraction systems given in Table 2 containing $C_{\mathrm{TA}}^{0}=0.3329 \mathrm{~mol} \mathrm{dm}^{-3}$ initial aqueousphase acid solution and TPA or DBA dissolved in diethyl sebacate, diethyl succinate, diethyl malonate, ethyl caprylate, ethyl valerate, and isoamyl alcohol diluents reveals that the physical extraction of valer- 
Table 2 -Variation of extractability factors $(E, D, Z)$ with concentration of components for extraction of valeric acid by tri-n-propyl amine (TPA)/diluent, dibenzyl amine $(D B A) /$ diluent, and pure diluent alone at $T=298 \pm 0.2 \mathrm{~K}\left(C_{T A}^{0}=0.3329 \mathrm{~mol} \mathrm{dm}^{-3}\right)^{a}$

\begin{tabular}{|c|c|c|c|c|c|}
\hline $\begin{array}{c}{\overline{C_{\mathrm{AM}}^{0}}}^{b} \\
\left.(\mathrm{~mol} \mathrm{dm})^{-3}\right)\end{array}$ & $\mathrm{pH}^{c}$ & $\begin{array}{c}C_{\mathrm{TA}}^{d} \\
\left(\mathrm{~mol} \mathrm{dm}{ }^{-3}\right)\end{array}$ & $\begin{array}{c}E \\
(\%)\end{array}$ & $D$ & $Z_{\mathrm{t}}$ \\
\hline \multicolumn{6}{|c|}{ TPA + Diethyl sebacate } \\
\hline $0.0000^{e}$ & 3.41 & 0.0282 & 91.53 & 10.805 & \\
\hline 0.2605 & 3.49 & 0.0241 & 92.76 & 12.813 & 1.185 \\
\hline 0.5244 & 3.54 & 0.0198 & 94.05 & 15.813 & 0.597 \\
\hline 0.7891 & 3.57 & 0.0157 & 95.28 & 20.204 & 0.402 \\
\hline $1.0553^{d}$ & 3.68 & 0.0113 & 96.61 & 28.460 & 0.305 \\
\hline \multicolumn{6}{|c|}{ TPA + Diethyl succinate } \\
\hline $0.0000^{e}$ & 3.45 & 0.0263 & 92.10 & 11.638 & \\
\hline 0.2591 & 3.52 & 0.0207 & 93.78 & 15.082 & 1.205 \\
\hline 0.5299 & 3.57 & 0.0142 & 95.73 & 22.444 & 0.601 \\
\hline 0.7894 & 3.71 & 0.0087 & 97.39 & 37.264 & 0.411 \\
\hline 1.0522 & 3.89 & 0.0050 & 98.50 & 65.580 & 0.312 \\
\hline \multicolumn{6}{|c|}{ TPA + Diethyl malonate } \\
\hline $0.0000^{e}$ & 3.44 & 0.0271 & 91.86 & 11.284 & \\
\hline 0.2640 & 3.58 & 0.0154 & 95.37 & 20.617 & 1.203 \\
\hline 0.5246 & 3.67 & 0.0110 & 96.70 & 29.264 & 0.614 \\
\hline 0.7886 & 3.70 & 0.0083 & 97.51 & 39.108 & 0.412 \\
\hline 1.0571 & 3.82 & 0.0063 & 98.11 & 51.841 & 0.309 \\
\hline \multicolumn{6}{|c|}{ TPA + Ethyl caprylate } \\
\hline $0.0000^{e}$ & 3.32 & 0.0383 & 88.50 & 7.692 & \\
\hline 0.2653 & 3.51 & 0.0242 & 92.73 & 12.756 & 1.164 \\
\hline 0.5269 & 3.63 & 0.0128 & 96.15 & 25.008 & 0.608 \\
\hline 0.7916 & 3.78 & 0.0075 & 97.75 & 43.387 & 0.411 \\
\hline 1.0558 & 3.86 & 0.0055 & 98.35 & 59.527 & 0.310 \\
\hline \multicolumn{6}{|c|}{ TPA + Ethyl valerate } \\
\hline $0.0000^{e}$ & 3.45 & 0.0262 & 92.13 & 11.706 & \\
\hline 0.2668 & 3.65 & 0.0125 & 96.25 & 25.632 & 1.201 \\
\hline 0.5255 & 3.73 & 0.0074 & 97.78 & 45.986 & 0.619 \\
\hline 0.7905 & 3.94 & 0.0046 & 98.62 & 71.370 & 0.415 \\
\hline 1.0513 & 4.11 & 0.0031 & 99.07 & 106.387 & 0.314 \\
\hline \multicolumn{6}{|c|}{ TPA + Isoamyl alcohol } \\
\hline $0.0000^{e}$ & 3.64 & 0.0127 & 96.19 & 25.213 & \\
\hline 0.2577 & 3.68 & 0.0098 & 97.06 & 32.969 & 1.254 \\
\hline 0.5264 & 3.71 & 0.0086 & 97.42 & 37.709 & 0.616 \\
\hline 0.7972 & 3.75 & 0.0073 & 97.81 & 44.603 & 0.408 \\
\hline 1.0550 & 3.83 & 0.0060 & 98.20 & 54.483 & 0.310 \\
\hline
\end{tabular}

\begin{tabular}{|c|c|c|c|c|c|}
\hline $\begin{array}{c}{\overline{C_{\mathrm{AM}}^{0}}}^{b} \\
\left(\mathrm{~mol} \mathrm{dm^{-3 }}\right)\end{array}$ & $\mathrm{pH}^{c}$ & $\begin{array}{c}C_{\mathrm{TA}}{ }^{d} \\
\left(\mathrm{~mol} \mathrm{dm}{ }^{-3}\right)\end{array}$ & $\begin{array}{c}E \\
(\%)\end{array}$ & $D$ & $Z_{\mathrm{t}}$ \\
\hline \multicolumn{6}{|c|}{ DBA + Diethyl sebacate } \\
\hline $0.0000^{e}$ & 3.41 & 0.0282 & 91.53 & 10.805 & \\
\hline 0.2576 & 3.52 & 0.0209 & 93.72 & 14.928 & 1.211 \\
\hline 0.5197 & 3.56 & 0.0175 & 94.74 & 18.023 & 0.607 \\
\hline 0.7884 & 3.63 & 0.0134 & 95.97 & 23.843 & 0.405 \\
\hline 1.0409 & 3.68 & 0.0106 & 96.82 & 30.406 & 0.310 \\
\hline \multicolumn{6}{|c|}{ DBA + Diethyl succinate } \\
\hline $0.0000^{e}$ & 3.45 & 0.0263 & 92.10 & 11.658 & \\
\hline 0.2581 & 3.54 & 0.0195 & 94.14 & 16.072 & 1.214 \\
\hline 0.5214 & 3.58 & 0.0153 & 95.40 & 20.758 & 0.609 \\
\hline 0.7823 & 3.67 & 0.0118 & 96.46 & 27.212 & 0.410 \\
\hline 1.0410 & 3.70 & 0.0109 & 96.73 & 29.541 & 0.309 \\
\hline
\end{tabular}

\begin{tabular}{|c|c|c|c|c|c|}
\hline \multicolumn{6}{|c|}{ DBA + Diethyl malonate } \\
\hline $0.0000^{e}$ & 3.44 & 0.0271 & 91.86 & 11.284 & \\
\hline 0.2597 & 3.52 & 0.0191 & 94.26 & 16.429 & 1.208 \\
\hline 0.5217 & 3.54 & 0.0173 & 94.80 & 18.243 & 0.605 \\
\hline 0.7869 & 3.56 & 0.0165 & 95.04 & 19.176 & 0.402 \\
\hline 1.0415 & 3.59 & 0.0146 & 95.61 & 21.801 & 0.306 \\
\hline \multicolumn{6}{|c|}{ DBA + Ethyl caprylate } \\
\hline $0.0000^{e}$ & 3.32 & 0.0383 & 88.50 & 7.692 & \\
\hline 0.2568 & 3.48 & 0.0265 & 92.04 & 11.562 & 1.193 \\
\hline 0.5198 & 3.55 & 0.0181 & 94.56 & 17.392 & 0.606 \\
\hline 0.7828 & 3.57 & 0.0147 & 95.58 & 21.646 & 0.406 \\
\hline 1.0415 & 3.64 & 0.0116 & 96.52 & 27.698 & 0.308 \\
\hline \multicolumn{6}{|c|}{ DBA + Ethyl valerate } \\
\hline $0.0000^{e}$ & 3.45 & 0.0262 & 92.13 & 11.706 & \\
\hline 0.2603 & 3.56 & 0.0178 & 94.65 & 17.702 & 1.211 \\
\hline 0.5211 & 3.58 & 0.0144 & 95.67 & 22.118 & 0.611 \\
\hline 0.7864 & 3.61 & 0.0123 & 96.31 & 26.065 & 0.408 \\
\hline 1.0411 & 3.65 & 0.0108 & 96.76 & 29.824 & 0.309 \\
\hline \multicolumn{6}{|c|}{ DBA + Isoamyl alcohol } \\
\hline $0.0000^{e}$ & 3.64 & 0.0127 & 96.19 & 25.213 & \\
\hline 0.2602 & 3.66 & 0.0108 & 96.76 & 29.824 & 1.238 \\
\hline 0.5203 & 3.70 & 0.0094 & 97.18 & 34.415 & 0.622 \\
\hline 0.7812 & 3.73 & 0.0084 & 97.48 & 38.631 & 0.415 \\
\hline 1.0408 & 3.79 & 0.0072 & 97.84 & 45.236 & 0.313 \\
\hline
\end{tabular}

${ }^{a}$ Initial concentration of valeric acid. ${ }^{b}$ Initial concentration of amine dissolved in oxygen-containing diluent. ${ }^{c}$ Aqueous phase acidity. ${ }^{d}$ Aqueous phase acid concentration; organic phase acid concentration $\overline{C_{\mathrm{TA}}}=C_{\mathrm{TA}}^{0}-C_{\mathrm{TA}}$. ${ }^{e}$ Properties referred to pure diluent alone (i.e., diethyl sebacate, diethyl succinate, diethyl malonate, ethyl caprylate, ethyl valerate, isoamyl alcohol). 
ic acid in pure diluent alone is reasonably high with a distribution ratio $\left(D_{0}\right)$ of about 25 for isoamyl alcohol $\left(D_{0}=25.1 ; E=96.2 \%\right)$, and less than 12 for others ranging from 7.7 for ethyl caprylate to 11.7 for ethyl valerate. In general, a high physical extractability of valeric acid by conventional solvents could be attributable to the strong hydrophobic nature of the acid due to a long R-chain structure and its relatively low ionizing strength $\left(\mathrm{p} K_{a}=4.842\right)$. This behavior is also related to the simultaneous effect of several specific solvent characteristics, such as polarity and hydrophobicity, probably varying dependently with the functional group configuration in the solvent structure. It turns out from the results given in Tables 1 and 2 that the solubilities of water and valeric acid in the organic phase vary with the structural properties and polarity of conventional solvents, following approximately the order: (i) for water, alcohol $>$ dibasic ester $>$ monobasic ester; (ii) for valeric acid, alcohol $>$ monobasic ester $>$ dibasic ester. This is perhaps not surprising considering the more polar structure of water as compared to that of valeric acid and organic solvent. As evident from Table 1, except for isoamyl alcohol, there is less tendency of the ester and amine coextraction in the aqueous phase, but inevitably water should carry a small amount of acid in the organic phase containing especially isoamyl alcohol, which can affect the phase behavior in an unexpected way.

Inspection of the experimental results in Table 2 reveals that, for both TPA/diluent and DBA/diluent systems, isoamyl alcohol and ethyl valerate diluents allow for achieving larger separation factors $D$ and $E$ as compared to those of dibasic ester and ethyl caprylate. Accordingly, the smallest extraction efficiency displayed by amine/diethyl sebacate and amine/ethyl caprylate would likely come from the long R-chain structure of these diluents that is eventually responsible for a steric hindrance in the organic phase. As shown in Table 2, a regular decrease in the overall loading factor $Z_{\mathrm{t}}$ with increasing the amine concentration $\overline{C_{\mathrm{AM}}^{0}}$ is also observed, but the range of decreasing is about equally large for all the examined TPA/diluent and DBA/diluent systems.

Regarding the magnitude of extraction factors in Table 2, it turns out that the largest extraction power is exhibited by TPA/isoamyl alcohol or DBA/ isoamyl alcohol yielding $D>29, Z_{\mathrm{t}}>0.3$ and $E>95 \%$ due to a complementary interaction effect of hydroxyl $(\mathrm{OH})$, carboxyl $(\mathrm{COOH})$, and amine $\left(\mathrm{NR}_{3}, \mathrm{NHR}_{2}\right)$ functional groups, promoting simultaneously physical extraction and chemical interaction. ${ }^{19,20}$ On the other hand, considering here $Z_{\mathrm{s}}$ and $S_{\mathrm{f}}^{\text {chem }}$ to be quantitative criteria for the degree of acidamine aggregation, it is observed from Figs. 1 and 2 that isoamyl alcohol diluent exhibits unimpressive solvation efficiency towards the acid-base complexes related to small $Z_{\mathrm{s}} \approx 0.07$ and $s_{\mathrm{f}}^{\text {chem }} \approx 0.06-0.21$, being indicative of the formation of non-overloaded (one acid per multiple amines) valeric acid-carrier complexes in the working range. In fact, as shown in Table 2 and Figs. 1 and 2, it is a foregone conclusion that $D, E$ and $s_{\mathrm{f}}^{\text {chem }}$ proportionally increase as the amine content increases, while $Z_{\mathrm{t}}$ and $Z_{\mathrm{s}}$ gradually decrease when increasing the amine concentration in the organic phase. In general, this type of phase behavior is prevalent for amine/diluent/acid systems, but the range of increasing (or decreasing) of $D, E, s_{\mathrm{f}}^{\text {chem }}, Z_{\mathrm{t}}$ and $Z_{\mathrm{s}}$ is intimately connected to the types and concentration levels of amine, diluent, and acid. ${ }^{7-14,20}$ But unexpectedly, here it is observed that, in the amine load working interval $0.25-1.05 \mathrm{~mol} \mathrm{dm}^{-3}$, the overall loading factors almost invariably range between $0.3<Z_{\mathrm{t}}<1.3$ for all the examined amine/diluent mixtures. As seen in Fig. 1, the stoichiometric loading factors $Z_{\mathrm{s}}$ for the studied amine concentration level are markedly low, ranging $Z_{\mathrm{s}}<0.12$. Regarding Fig. 2, the same remarks hold for the chemical separation factors $S_{\mathrm{f}}^{\text {chem }}$ varying in the range $S_{\mathrm{f}}^{\text {chem }} \approx$ $0.07-0.30$, which in turn manifests the fact that the contribution of chemical interaction to the overall acid separation is about 3-12 times smaller than that of physical extraction. It is concluded from Figs. 1-3 that all the studied amine/diluent solvent mixtures generally exhibit low chemical interactiondependent factors $0.06\left\langle Z_{\mathrm{s}}<0.12,0.07<s_{\mathrm{f}}^{\text {chem }}<0.3\right.$

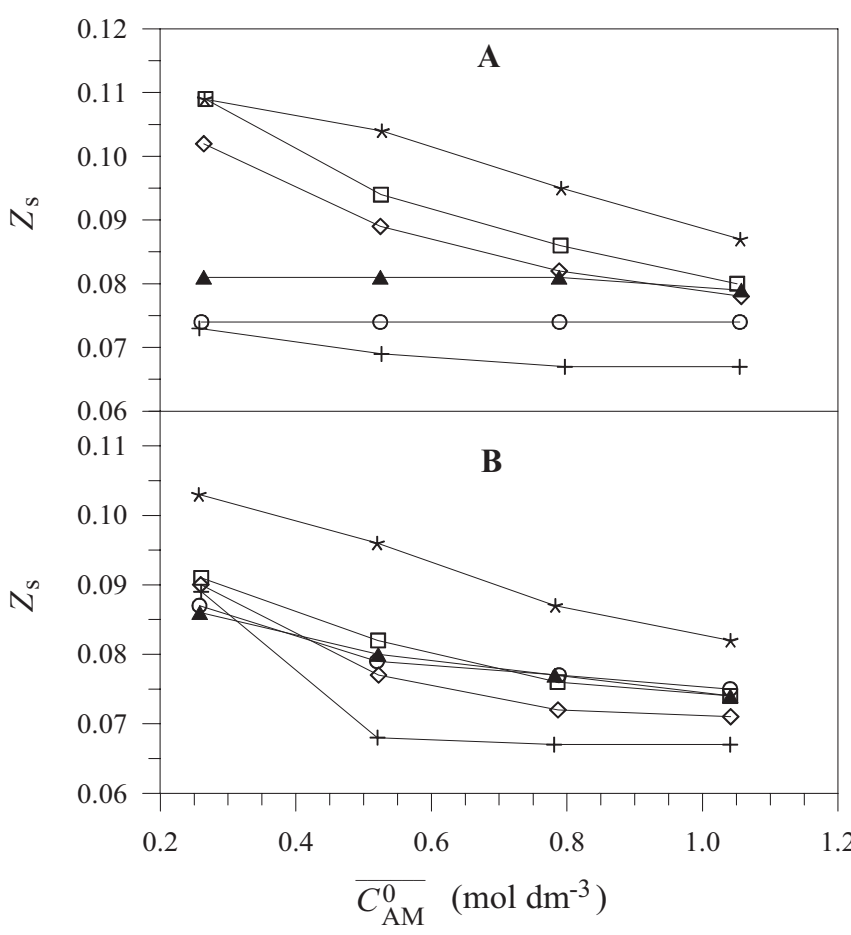

Fig. 1 - Variation of stoichiometric loading factor $Z_{\mathrm{s}}$ with organic phase amine concentration $\overline{C_{A M}^{0}}\left(\mathrm{~mol} \mathrm{dm}{ }^{-3}\right) ; A$. TPA/ diluent, B. DBA/diluent; O diethyl sebacate, $\mathbf{\Delta}$ diethyl succinate, $\diamond$ diethyl malonate, $\star$ ethyl caprylate, $\square$ ethyl valerate, + isoamyl alcohol; $\left(C_{T A}^{0}=0.3329 \mathrm{~mol} \mathrm{dm}^{-3}\right)$ 
and $0.06<R<0.39$ indicating that moderately strong interactive forces should dominate during valeric acid-amine complexation. Specifically, it is presumed that the formation of non-overloaded $(1: 1$ and $1: 2)$ or (1:1 and 1:3) ion-pair acid-amine complexes with a lowered solvation degree by the diluent would likely proceed at the complaxation stage of extraction. Together with this, the differences among $D$ and $S E$ factors provided in Table 2 and Fig. 4 indicate that the complementary effect of chemical interaction and physical extraction is a critical factor for TPA- or DBA-based reactive extraction of valeric acid.

However, it is essential that this phenomenon should have a significant impact on the implementation of a selected extraction method. As seen in Table 2 and Figs. 1 and 2, valeric acid is physically easier to extract by the protic isoamyl alcohol alone as compared to others, whereas the magnitude of the acid-amine complexation is relatively larger for amine/monobasic ester (ethyl caprylate and ethyl valerate) regarding the magnitude of $Z_{\mathrm{s}}$ and $s_{\mathrm{f}}^{\text {chem }}$ factors. It turns out from Figs. 1 and 2 that the controlling factor for acid-amine chemical association is the solvation efficiency of diluent ranging as follows: ethyl caprylate $>$ ethyl valerate $>$ diethyl succinate $\approx$ diethyl malonate $>$ diethyl sebacate $>$ isoamyl alcohol. It is worth mentioning here again that $S E$ is quantitatively assessed as a criterion for a synergism in extraction since it includes both chemical and physical interaction terms. In view of $S E$ factors in Fig. 4, the synergistic extraction power of the solvent mixture increases in the order: isoamyl alcohol $>$ dibasic ester $>$ monobasic ester, and TPA $>$ DBA. Typically, TPA is a more effective separation agent than DBA for the identical diluents checked according to $s_{\mathrm{f}}^{\text {chem }}, D$ and $S E$ factors. This could be attributable to the steric hindrance and the resonance $\pi$ electron effect in the DBA structure and the more structured (or equivalent less polar) formula of TPA due to the larger number of organic radicals in the latter. Unfortunately, there is a lack of experimental data reflecting the range of the steric hindrance and resonance effect provided by an extractant in solution; however, here the geometric structure of the solvent molecule is thought to be an appropriate reference of the expected magnitude of the steric effect along the entire composition range.

It is apparent from Fig. 1 that the maximum stoichiometric loading $\left(Z_{\mathrm{s}, \max }\right)$ corresponding to the plateau in the loading curve appears at $Z_{\mathrm{s}, \max }<1$, signifying a tendency toward the formation of two types of non-overloaded valeric acid amine $_{q}$ structures, i.e. an aggregation related to one acid per multiple amines ( $p: q=1: 2$ or $p: q=1: 3)$, and an equimolar acid-amine interaction $(p: q=1: 1)$. This fact seems to be a common strategy for designing

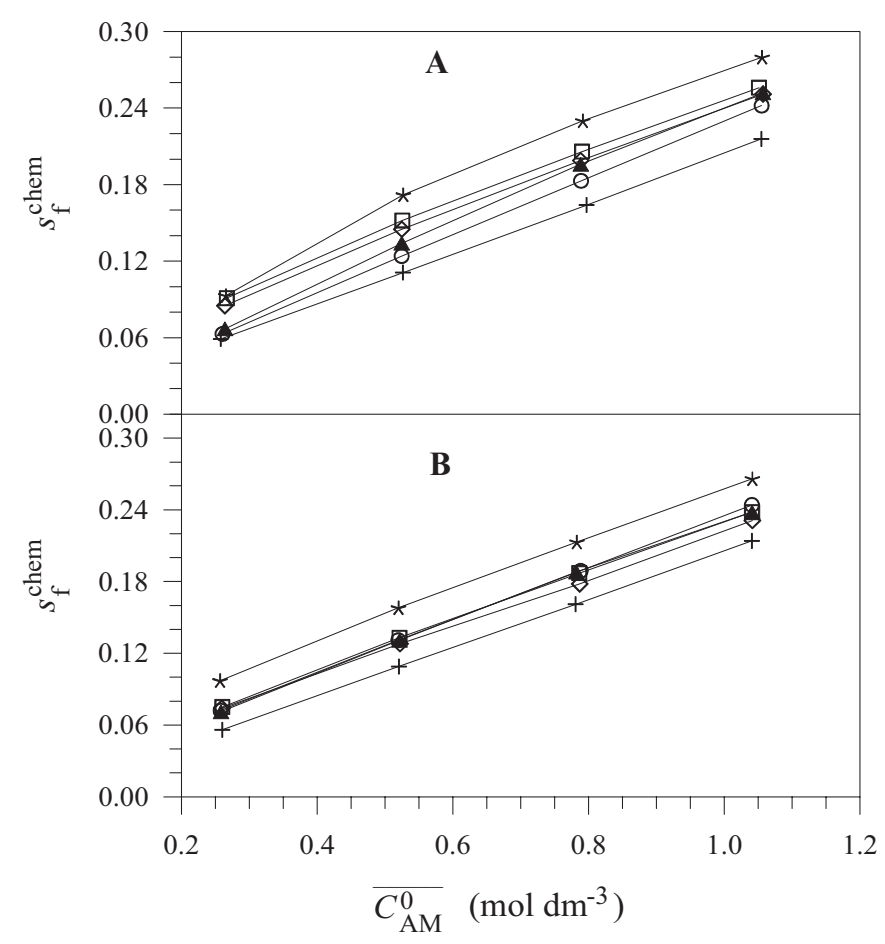

Fig. 2 - Variation of chemical separation factor $s_{\mathrm{f}}^{\text {chem }}$ with organic phase amine concentration $\overline{C_{A M}^{0}}\left(\mathrm{~mol} \mathrm{dm^{-3 }}\right) ; A$. TPAl diluent, $B$. DBA/diluent; $\bigcirc$ diethyl sebacate, $\mathbf{\Delta}$ diethyl succinate, $\diamond$ diethyl malonate, $\star$ ethyl caprylate, $\square$ ethyl valerate, + isoamyl alcohol; $\left(C_{T A}^{0}=0.3329 \mathrm{~mol} \mathrm{dm}^{-3}\right)$

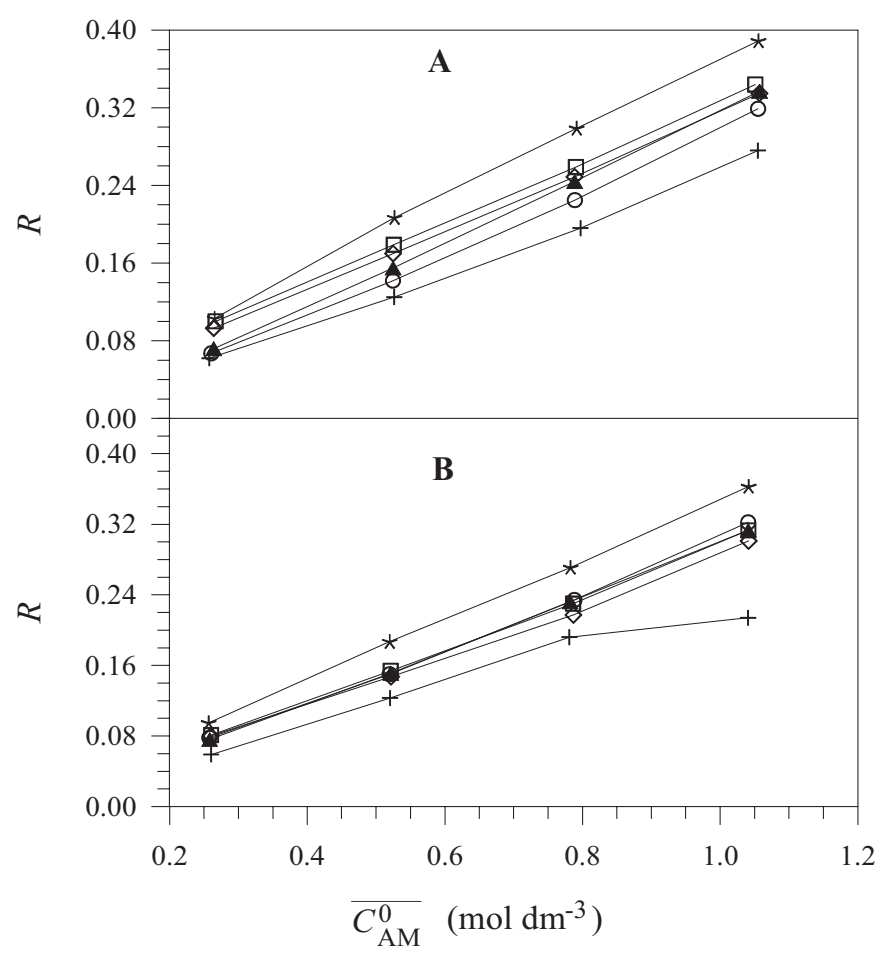

Fig. 3 - Variation of separation ratio optimization factor $R$ with organic phase amine concentration $\overline{C_{A M}^{0}}\left(\mathrm{~mol} \mathrm{dm}^{-3}\right)$; A. TPA/diluent, B. DBA/diluent; O diethyl sebacate, $\mathbf{\Delta}$ diethyl succinate, $\diamond$ diethyl malonate, $\star$ ethyl caprylate, $\square$ ethyl valerate, + isoamyl alcohol; $\left(C_{T A}^{0}=0.3329 \mathrm{~mol} \mathrm{dm}^{-3}\right)$ 
the reactive extraction of valeric acid. For the sake of simplicity, we will consider here a maximum stoichiometric loading $Z_{\text {s,max }}$ to be 0.03 (about 22$30 \%$ ) larger than the upper limit value of $Z$ obtained from Fig. 1 as follows: 0.104, 0.111, 0.132, $0.139,0.139$ and 0.103 for TPA/diluent and 0.117 , $0.116,0.120,0.133,0.121$ and 0.099 for DBA/diluent for diethyl sebacate, diethyl succinate, diethyl malonate, ethyl caprylate, ethyl valerate and isoamyl alcohol, respectively. Regarding the above $Z_{\text {s } \max }$ values, one may conclude that the examined diluents affect almost invariably the diluent-complex aggregation through hydrogen bonding or dipole-dipole interaction. Weak interactive forces producing low solvation degree of acid-amine complexes have been obtained for all the tested solvents yielding $Z_{\text {s,max }}<0.15$. In comparison with isoamyl alcohol and dibasic ester, monobasic ester allows for higher complex solvation efficiency in the organic phase. It ought to be pointed out that larger distribution of the acid in pure diluent alone mostly is not a guarantee for achieving better complexation efficiency of the amine. ${ }^{20}$

Consequently, the used amines do not function well in extracting valeric acid as proven by low $Z_{\mathrm{s}}$ values. However, isoamyl alcohol, as a less hydrophobic diluent, can extract a significant amount of valeric acid by itself, thus eventually improving the overall extraction. The observed $Z$ and $S E$ factors from Table 2 and Fig. 4 show that TPA is a slightly more effective carrier than DBA for which the aromatic ring is likely responsible for a steric effect. For both amine samples, there is a tendency toward an acid-carrier complexation including predominantly one mole acid per multiple moles extractant related to $Z_{\mathrm{s}}<0.12$ and $s_{\mathrm{f}}^{\text {chem }}<0.3$.

\section{Optimization criteria for amine extraction of valeric acid}

An important aspect of liquid-liquid equilibrium systems containing a reactive amine extractant is conducted on optimizing the extraction process. While various models, based on hydrogen-bond theory, group-contribution method, and dipole-dipole interaction concepts exist for reactive extraction systems, only a few works have focused on optimizing analytically the extraction efficiency of a LLE system. However, the literature revealed very little insight relating to the validity of a generalized method for the prediction of optimum extraction limits pertaining to reactive extraction systems. ${ }^{27-29}$

The study deals with a new conceptual definition for optimum extraction as the locus of the newly proposed separation ratio optimization factor $R$ and synergistic enhancement factor $S E$ being used as the optimization criteria. The goal is to determine the most suitable extract composition for the acid recovery against practically permissible optimum concentration range of the solvent mixture. A feasible way to achieve these purposes lies in processing an effective optimization method depending on $R$ and $S E$ factors. To simplify the complexity of the optimization problem, only the ranges of $R$ and $S E$ factors should be subjected to formulation of an optimization structure along with applying the derivative variation method described earlier by Senol. ${ }^{27-29}$ This method implies that: (1) the contribution of the derivatives to the optimized property is validated by the slope analysis, and (2) the identification of the optimum conditions is governed by the range of changes in the derivative value.

Development of a new conceptual definition of optimum extraction conditions for the acid recovery requires an interpretation of $R=f\left(x_{i v}\right)$ and $S E=f\left(1 / x_{i v}\right)$ curves both graphically and analytically, where $x_{i v}$ stands for the independent variable defined as $x_{i v}=\overline{C_{\mathrm{AM}}^{0}} / C_{\mathrm{TA}}$. To reduce the complexity of the optimization problem, an uncoupling and an independent dealing with the slopes of the observed and modeled curves will be processed, where the variation profile of the modeled quantity $(R$ or $S E$ ) can be expressed by a non-homogeneous differential equation, eq. (9).

$$
\begin{gathered}
R=R_{\max }\left[1-\exp \left(r x_{i v}\right)\right] ; \\
S E=S E_{\max }\left[1-\exp \left(s x_{i v}^{-1}\right)\right]
\end{gathered}
$$

$R_{\max }$ and $S E_{\max }$ are the maximum values of extraction factors. The substance-dependent adjustable coefficients $r$ and $s$ have been estimated by means of linear regression. The derivative variation test (slope analysis) of the considered variables has been performed using linear programming algorithm. ${ }^{30,31}$ The maximum extraction factors $R_{\max }$ and $S E_{\max }$, as well as the adjustable coefficients $r$ and $s$ obtained from eq. (9) are as follows, (a) for TPA: $R_{\max }=0.42, S E_{\text {max }}=17.44(r=-0.015357, s=$ -33.418 diethyl sebacate); $R_{\max }=0.44, S E_{\max }=$ $16.40(r=-0.008187, s=-43.348$ diethyl succinate); $R_{\max }=0.44, S E_{\max }=13.26(r=-0.009135, s$ $=-58.279$ diethyl malonate); $R_{\text {max }}=0.49, S E_{\text {max }}=$ 12.21 ( $r=-0.009456, s=-41.618$ ethyl caprylate); $R_{\max }=0.44, S E_{\max }=12.53(r=-0.005289, s=$ -80.832 ethyl valerate); $R_{\max }=0.38, S E_{\max }=18.55$ ( $r=-0.006974, s=-79.487$ isoamyl alcohol), (b) for DBA: $R_{\text {max }}=0.42, S E_{\max }=15.32(r=-0.014654$, $s=-38.735$ diethyl sebacate); $R_{\max }=0.41, S E_{\max }=$ $15.64(r=-0.014060, s=-41.852$ diethyl succinate); $R_{\text {max }}=0.40, S E_{\max }=14.95(r=-0.017567, s$ $=-39.709$ diethyl malonate); $R_{\max }=0.46, S E_{\max }=$ 13.04 ( $r=-0.017632, s=-32.539$ ethyl caprylate); $R_{\max }=0.41, S E_{\max }=14.76(r=-0.013999, s=$ -45.411 ethyl valerate); $R_{\max }=0.41, S E_{\max }=19.44$ $(r=-0.008290, s=-71.060$ isoamyl alcohol). 
The present amine/diluent/valeric acid reactive extraction system may be categorized as a system exhibiting large physical solubility of the distributed acid in pure diluent alone with $D_{0}>7$. An interpretation of the optimum conditions of relevant systems through analyzing the derivative variation profile (slopes) of the observed (Figs. 3 and 4) and modeled (eq. (9)) properties results in the following quantitative ranges of the $R$ factor attributed to the amine extraction of valeric acid.

$0<R<0.5$ (extractant is a poor separating agent)

$0.5<R<1$ (extractant is moderately effective)

$1<R<3 \quad$ (extractant is an excellent separating agent)

\section{$R>3 \quad$ (very large extractant load is used)}

Since the physical extraction of valeric acid by the diluent is prevalent in the examined extraction systems, the ranges of the synergistic (overall) extraction factors $Z_{\mathrm{t}}$ and $S E$ decrease with increasing the volume fraction of the amine. In this case, the most appropriate synergistic extraction power of relevant amine/diluent system can be identified due to the $S E$ ranges regarding the slope variation profile (slope changes) of the observed (Fig. 4) and modeled (eq. (9)) curves defined as follows:

$S E<4 \quad$ (very large extractant load is used)

$4<S E<7$ (solvent system is moderately effective)

$7<S E<20$ (solvent system is an excellent separating agent)

$S E>20 \quad$ (solvent system works in favor of physical extraction).

By analyzing the variation profiles of the quantities in question, it is recognized that the most appropriate ranges are $0.5<\mathrm{R}<3$ and $4<S E<20$ where the curve slope is changed considerably. However, both $R$ and $S E$ factors are varying with the extractant content in the solvent mixture, and their optimum values are intimately connected to the physical solubility of the acid in pure diluent alone. For a practically insoluble acid in the selected diluent alone and carrier, the optimization factors $R$ and $S E$ are devoid of the physical meaning. This leaves us with the conclusion that the proposed optimization structure based on $R$ and $S E$ factors is capable of representing reliably the behavior of a reactive extraction system involving a physically very soluble valeric acid in pure diluent alone with $D_{0}>7$.

Depending on the above $R$ and $S E$ conditions, an analysis was conducted of the observed (Figs. 3 and 4) and modeled (eq. (9)) performance results in optimum extraction conditions dictating preferably the use of monobasic esters and isoamyl alcohol as



Fig. 4 - Variation of synergistic enhancement factor SE with organic phase amine concentration $\overline{C_{A M}^{0}}\left(\mathrm{~mol} \mathrm{dm^{-3 } ) ; A}\right.$. TPA/ diluent, B. DBA/diluent; 0 diethyl sebacate, \ diethyl succinate, $\diamond$ diethyl malonate, $\star$ ethyl caprylate, $\square$ ethyl valerate, + isoamyl alcohol; $\left(C_{T A}^{0}=0.3329 \mathrm{~mol} \mathrm{dm^{-3 }}\right)$

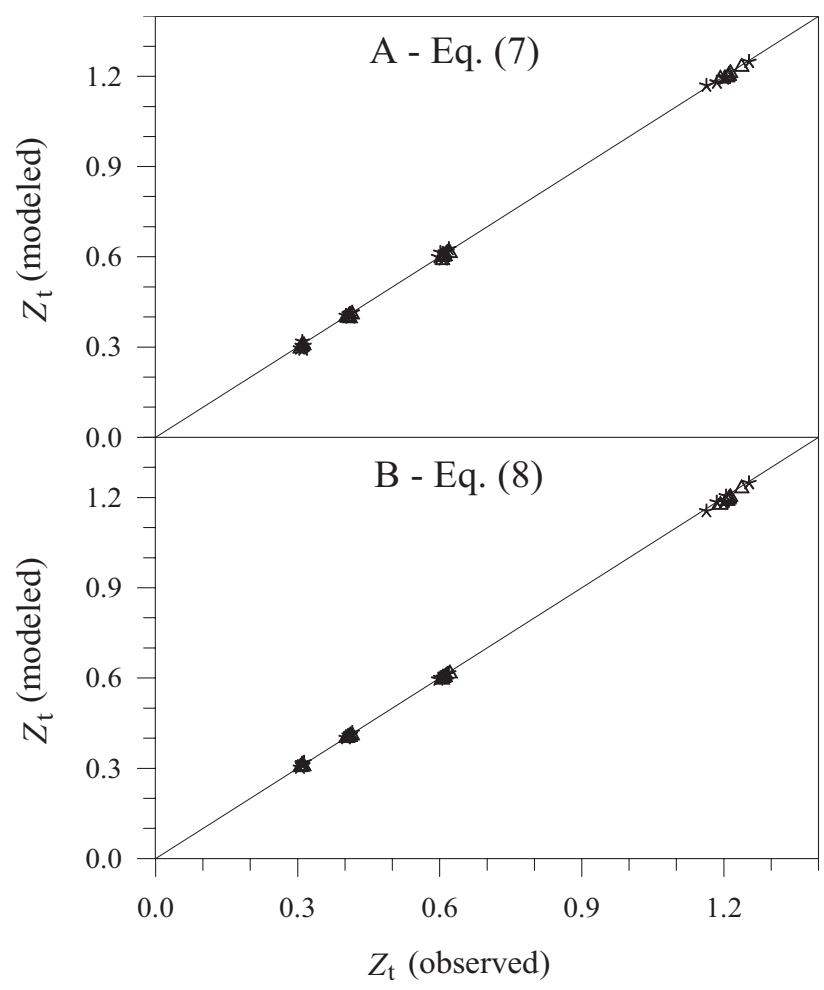

Fig. 5 - Reliability analysis of mass-action law models as a plot of the model performance $(Z)$ against the observed properties: * TPA/diluent, $\triangle$ DBA/diluent. (A) Chemodel, eq. (7); (B) Langmuir model, eq. (8) 
Table 3 -Extraction constants $\beta_{p q}$ and $\beta_{L}$ of eqs. (7) and (8), root-mean-square deviation $(\sigma)$, and mean relative error $(\bar{e})^{a}$ of model estimates for valeric acid-amine complexation

\begin{tabular}{|c|c|c|c|c|c|c|c|c|}
\hline \multirow{2}{*}{\multicolumn{2}{|c|}{ Syste }} & \multicolumn{3}{|c|}{ Modified Langmuir model, eq. (8) } & \multicolumn{4}{|c|}{ Mass-action law chemodel, eq. (7) } \\
\hline & & $\beta_{L} ;\left(z=Z_{\mathrm{s}, \max }\right)^{b}$ & $\sigma$ & $\bar{e}\left(Z_{\mathrm{t}}\right)$ & $\beta_{p q 1} ;(p, q)^{c}$ & $\beta_{p q 2} ;(p, q)^{c}$ & (7) & $\bar{e}\left(Z_{\mathrm{t}}\right)$ \\
\hline \multirow[t]{2}{*}{$\mathrm{TPA}^{e}+$ Diethyl sebacate } & $\mathrm{S}^{d}$ & $0.3779 \cdot 10^{1} ;(0.104)$ & 0.0005 & 0.08 & $0.4416 \cdot 10^{1} ;(1,1)$ & & 0.019 & 3.85 \\
\hline & $\mathrm{T}^{d}$ & & & & $0.2254 \cdot 10^{1} ;(1,1)$ & $0.5198 \cdot 10^{1} ;(1,2)$ & 0.005 & 1.08 \\
\hline \multirow[t]{2}{*}{ TPA + Diethyl succinate } & $\mathrm{S}$ & $0.4826 \cdot 10^{1} ;(0.111)$ & 0.0007 & 0.12 & $0.6127 \cdot 10^{1} ;(1,1)$ & & 0.035 & 7.22 \\
\hline & $\mathrm{T}$ & & & & $0.6105 \cdot 10^{0} ;(1,1)$ & $0.1597 \cdot 10^{2} ;(1,2)$ & 0.014 & 2.31 \\
\hline \multirow[t]{2}{*}{ TPA + Diethyl malonate } & $\mathrm{S}$ & $0.3541 \cdot 10^{1} ;(0.132)$ & 0.0081 & 1.19 & $0.9777 \cdot 10^{1} ;(1,1)$ & & 0.019 & 3.49 \\
\hline & $\mathrm{T}$ & & & & $0.6017 \cdot 10^{1} ;(1,1)$ & $0.9271 \cdot 10^{1} ;(1,2)$ & 0.003 & 0.52 \\
\hline \multirow[t]{2}{*}{ TPA + Ethyl caprylate } & $\mathrm{S}$ & $0.4571 \cdot 10^{1} ;(0.139)$ & 0.0062 & 1.18 & $0.7651 \cdot 10^{1} ;(1,1)$ & & 0.044 & 8.99 \\
\hline & $\mathrm{T}$ & & & & $0.5432 \cdot 10^{1} ;(1,1)$ & $0.2367 \cdot 10^{2} ;(1,3)$ & 0.010 & 2.09 \\
\hline \multirow[t]{2}{*}{ TPA + Ethyl valerate } & $\mathrm{S}$ & $0.3943 \cdot 10^{1} ;(0.139)$ & 0.0085 & 1.25 & $0.1436 \cdot 10^{2} ;(1,1)$ & & 0.035 & 6.62 \\
\hline & $\mathrm{T}$ & & & & $0.3803 \cdot 10^{1} ;(1,1)$ & $0.3021 \cdot 10^{2} ;(1,2)$ & 0.006 & 1.18 \\
\hline \multirow[t]{2}{*}{ TPA + Isoamyl alcohol } & $\mathrm{S}$ & $0.3358 \cdot 10^{1} ;(0.103)$ & 0.0022 & 0.30 & $0.9902 \cdot 10^{1} ;(1,1)$ & & 0.011 & 2.04 \\
\hline & $\mathrm{T}$ & & & & $0.7264 \cdot 10^{1} ;(1,1)$ & $0.5875 \cdot 10^{1} ;(1,2)$ & 0.003 & 0.68 \\
\hline \multirow[t]{2}{*}{$\mathrm{DBA}^{e}+$ Diethyl sebacate } & $\mathrm{S}$ & $0.3470 \cdot 10^{1} ;(0.117)$ & 0.0040 & 0.54 & $0.5694 \cdot 10^{1} ;(1,1)$ & & 0.016 & 3.18 \\
\hline & $\mathrm{T}$ & & & & $0.4928 \cdot 10^{1} ;(1,1)$ & $0.5029 \cdot 10^{1} ;(1,3)$ & 0.002 & 0.27 \\
\hline \multirow[t]{2}{*}{ DBA + Diethyl succinate } & $\mathrm{S}$ & $0.3512 \cdot 10^{1} ;(0.116)$ & 0.0037 & 0.57 & $0.6195 \cdot 10^{1} ;(1,1)$ & & 0.014 & 2.62 \\
\hline & $\mathrm{T}$ & & & & $0.5615 \cdot 10^{1} ;(1,1)$ & $0.4273 \cdot 10^{1} ;(1,3)$ & 0.005 & 0.92 \\
\hline \multirow[t]{2}{*}{ DBA + Diethyl malonate } & $\mathrm{S}$ & $0.2860 \cdot 10^{1} ;(0.120)$ & 0.0073 & 0.99 & $0.5212 \cdot 10^{1} ;(1,1)$ & & 0.003 & 0.70 \\
\hline & $\mathrm{T}$ & & & & $0.5678 \cdot 10^{1} ;(1,1)$ & $0.2434 \cdot 10^{-1} ;(1,3)$ & 0.004 & 0.71 \\
\hline \multirow[t]{2}{*}{ DBA + Ethyl caprylate } & $\mathrm{S}$ & $0.3752 \cdot 10^{1} ;(0.133)$ & 0.0070 & 1.23 & $0.5843 \cdot 10^{1} ;(1,1)$ & & 0.020 & 3.48 \\
\hline & $\mathrm{T}$ & & & & $0.5228 \cdot 10^{1} ;(1,1)$ & $0.5339 \cdot 10^{1} ;(1,3)$ & 0.006 & 0.75 \\
\hline \multirow[t]{2}{*}{ DBA + Ethyl valerate } & $\mathrm{S}$ & $0.3285 \cdot 10^{1} ;(0.121)$ & 0.0061 & 0.91 & $0.6698 \cdot 10^{1} ;(1,1)$ & & 0.008 & 1.48 \\
\hline & $\mathrm{T}$ & & & & $0.6553 \cdot 10^{1} ;(1,1)$ & $0.2563 \cdot 10^{1} ;(1,3)$ & 0.001 & 0.13 \\
\hline \multirow[t]{2}{*}{ DBA + Isoamyl alcohol } & $\mathrm{S}$ & $0.3467 \cdot 10^{1} ;(0.099)$ & 0.0005 & 0.08 & $0.8551 \cdot 10^{1} ;(1,1)$ & & 0.009 & 1.73 \\
\hline & $\mathrm{T}$ & & & & $0.7755 \cdot 10^{1} ;(1,1)$ & $0.4847 \cdot 10^{1} ;(1,3)$ & 0.001 & 0.13 \\
\hline
\end{tabular}

$a_{\bar{e}} \bar{e}(100 / N) \sum_{N=1}^{N}\left|\left(Z_{\mathrm{t}, \mathrm{obs}}-Z_{\mathrm{t}, \mathrm{mod}}\right) / Z_{\mathrm{t}, \mathrm{obs}}\right|, \sigma=\left[\sum_{i=1}^{N}\left(Z_{\mathrm{t}, \mathrm{obs}}-Z_{\mathrm{t}, \mathrm{mod}}\right)^{2} / N\right]^{0.5}$.

${ }^{b}$ Langmuir extraction constant $\left(\beta_{\mathrm{L}}\right)$ in $\left(\mathrm{mol} \mathrm{dm}^{-3}\right)^{-z}$ due to eq. (8). Maximum loading values $z=Z_{s, \max }$ are given in parenthesis.

${ }^{c}$ Extraction constant $\left(\beta_{p q}\right)$ in $\left(\mathrm{mol} \mathrm{dm}^{-3}\right)^{1-p-q}$ for a given acid-amine $(p, q)$ aggregation due to eq. (7).

${ }^{d}$ One (S) or two (T) complex formation considered.

${ }^{e}$ TPA, tri- $n$-propyl amine; DBA, dibenzyl amine.

the most appropriate diluents in combination with TPA or DBA. The latter diluents provide a relatively appropriate medium for valeric acid and acid-amine complexes to stay in the organic phase as compared to less effective dibasic esters. Disapprovingly, all the studied diluents consistently yielded very small $R$ factors $(R<0.4)$ with regard to the tested amine concentration range, indicating that generally weaker interactive forces between the diluent and the formed complexes appear during the complexation stage. These concepts are supported by the results for $S E$ factor from Fig. 4, signifying preferably an effective synergistic separation of valeric acid by amine/ester and amine/isoamyl alco- 
hol systems at lower concentration levels of the carrier. Consequently, monobasic esters in combination with the amines appear to be the most effective solvating agents for the formed acid-amine complexes, while isoamyl alcohol yields the largest synergistic extraction efficiency among the considered amine/ diluent systems.

\section{Statistical analysis of equilibrium models}

The equilibrium results in Table 2 were interpreted in terms of the mass action law chemodel and modified Langmuir approach using the regressed overall apparent extraction constants $\beta_{p q}$ and $\beta_{\mathrm{L}}$ due to eqs. (7) and (8), respectively. Fig. 5 illustrates the graphical confidence tests of the model performance against the observed property pertaining to eqs. (7) and (8). However, the chemodel, eq. (7), presumes the formation of either one or at least two complexes. Estimates were performed using the multivariable procedures of linpack algorithm $^{31}$ for one, two or three selected appropriate complex combinations regarding $Z_{\mathrm{s}}$. The best fits display the approach comprising the formation of one ( $p: q=1: 1$ for TPA and DBA) or simultaneous two associated acid -extractant $_{q}(p, q)$ structures of different stoichiometry depending on the diluent used, i.e. (a) TPA: $(1,1)$ and $(1,3)$ for ethyl caprylate and $(1,1)$ and $(1,2)$ for other diluents; (b) DBA: $(1,1)$ and $(1,3)$ for all the examined diluents. The Langmuir model, eq. (8), has been derived considering the formation of only one associated structure $p: q=z: 1=Z_{s, \max }$. The regressed equilibrium constants $\left(\beta_{p q}\right)$ for one $(\mathrm{S})$ and two $(\mathrm{T})$ selected individual complexes and Langmuir extraction constant $\left(\beta_{\mathrm{L}}\right)$ in terms of the mean relative error $\bar{e}=(100 / N) \sum_{i=1}^{N}\left|\left(Z_{\mathrm{t}, \mathrm{obs}}-Z_{\mathrm{t}, \bmod }\right) / Z_{\mathrm{t}, \mathrm{obs}}\right|(\%)$ and rootmean-square deviation $\sigma=\left[\sum_{i=1}^{N}\left(Z_{\mathrm{t}, \mathrm{obs}}-Z_{\mathrm{t}, \mathrm{mod}}\right)^{2} / N\right]^{0.5}$ of the $Z_{\mathrm{t}}$ factor are provided in Table 3. Referring to the $\beta_{p q}$ definition and considered complex formation from Table 3 , the chemodel (eq. (7)) reproduces the overall $Z_{\mathrm{t}}$ data quite accurately, yielding the mean deviations of $\bar{e}\left(Z_{\mathrm{t}}\right)=3.8 \%\left(\sigma\left(Z_{\mathrm{t}}\right)=0.019\right)$, and $\bar{e}\left(Z_{\mathrm{t}}\right)=0.9 \% \quad\left(\sigma\left(Z_{\mathrm{t}}\right)=0.005\right)$ for one and two complex formation, respectively. The chemodel, eq. (7), matches the experimental data for two considered complex formations slightly more precisely in comparison with one complex formation due to an increased number of degrees of freedom. Additionally, eq. (7) reproduces the observed $Z_{\mathrm{t}}$ properties for the DBA/diluent system more reliably, yielding $\bar{e}\left(Z_{\mathrm{t}}\right)=0.5 \% \quad\left(\sigma\left(Z_{\mathrm{t}}\right)=0.003\right)$ as compared to $\bar{e}\left(Z_{\mathrm{t}}\right)=1.3 \%\left(\sigma\left(Z_{\mathrm{t}}\right)=0.007\right)$ for the TPA/diluent system considering two complex formations.
The estimated $\beta_{\mathrm{L}}$ values in $\left.(\mathrm{mol} \mathrm{dm})^{-3}\right)^{-z}$ due to eq. (8) and statistical deviation results in terms of $Z_{\mathrm{t}}$ are given in Table 3 . This table also presents the maximum loading values $\left(z=Z_{\mathrm{s}, \max }\right)$ of relevant amine/diluent systems used in eq. (8). Statistical analysis of eq. (8) results in a quite precise representation of the model performance, reproducing data with an average error of $\bar{e}\left(Z_{\mathrm{t}}\right)=0.7 \%$ $\left(\sigma\left(Z_{t}\right)=0.005\right)$. The reliability analysis of eqs. (7) and (8) has also been performed graphically through a plot of the model performance against the observed property with respect to the selected two (T) complex formations for eq. (7) and one complex relative to $z=Z_{\mathrm{s}, \max }$ for eq. (8), as depicted in Fig. 5 .

Both eqs. (7) and (8) are expected to be reliable in data fit for the associated reactive extraction systems because the distribution along the diagonal line remained in an acceptable narrow band (Fig. 5 ). Further, the random pattern of comparison points at each side of the diagonal line implies that the existing mass-action law models are almost free of systematical errors. Referring to Fig. 5, one may conclude that the models yielded a relatively fair distribution verifying the goodness-of-fit.

\section{Conclusions}

A detailed study on the reactive extraction of valeric acid from aqueous solutions by TPA/diluent and DBA/diluent has been performed. The work leads to the following conclusions:

- The extraction efficiency of valeric acid by amine/diluent mixture is dependent almost equally strongly on the structural properties of the carrier and the solvation capability of the examined diluent. The physical extraction favors over the chemical interaction. The synergistic extraction power of amine/diluent system decreases in the order: isoamyl alcohol $>$ ethyl valerate $>$ diethyl malonate $>$ diethyl succinate $\approx$ diethyl sebacate $>$ ethyl caprylate. The more structured TPA is slightly more effective than the less structured DBA. The resonance effect of aromatic $\pi$ electron system and the steric hindrance are other controlling factors for DBA.

- Characterization of acid-amine complexation is intimately connected to the polarity and hydrogen bonding affinity of the diluent. A favorable valeric acid $_{p}$-amine ${ }_{q}$ complexation pertains to the formation of $(1: 1)$ and $(1: 2)$ complexes for TPA, and (1:1) and (1:3) complexes for DBA.

- The proposed $R$ and $S E$ factors provide an analytical structure for prediction of optimum extraction. The evaluated optimization structure depending on $R$ and $S E$ factors is of particular interest 
in dealing with complex non-linear phenomena, such as that in a reactive extraction system.

- The mass action law models, eqs. (7) and (8), were able to reproduce the experimental data satisfactorily yielding mean errors of $0.9 \%$ and 0.7 $\%$, respectively.

\section{ACKNOWLEDGMENTS}

This work was supported by the Research Fund of Istanbul University; Project number 4402.

\section{Nomenclature}

\section{Symbols}

$\overline{C_{\mathrm{AM}}}-$ Concentration of non-complexed amine, $\mathrm{mol} \mathrm{dm} \mathrm{dm}^{-3}$

$\overline{C_{\mathrm{AM}}^{0}} \quad-$ Initial concentration of amine in solvent mixture, $\mathrm{mol} \mathrm{dm}^{-3}$

$\overline{C_{\mathrm{d}}}-$ Concentration of acid extracted by diluent, mol dm ${ }^{-3}$

$C_{\mathrm{H}^{+}} \quad-$ Proton concentration of acid in aqueous phase, mol dm ${ }^{-3}$

$C_{\mathrm{HA}}-$ Concentration of undissociated acid in aqueous phase, mol dm${ }^{-3}$

$\overline{C_{\mathrm{HA}}}-$ Overall concentration of complexed acid, mol dm ${ }^{-3}$

- Concentration of acid -amine $_{q}$ complex, mol $\mathrm{dm}^{-3}$

$C_{\mathrm{TA}}-$ Overall concentration of acid in aqueous phase, mol dm ${ }^{-3}$

- Overall concentration of acid in organic phase, mol dm ${ }^{-3}$

$C_{\mathrm{TA}}^{0} \quad-$ Initial concentration of acid, $\mathrm{mol} \mathrm{dm} \mathrm{dm}^{-3}$

- Concentration of acid extracted by diluentalone, $\mathrm{mol} \mathrm{dm}^{-3}$

D - Distribution ratio of acid relative to solvent mixture

$D_{0} \quad-$ Distribution ratio of acid relative to pure diluent alone

E - Extraction degree of acid relative to solvent mixture, $\%$

$\bar{e} \quad-$ Mean relative error, $\bar{e}=(100 / \mathrm{N}) \sum_{i=1}^{N}\left|\left(Y_{i, \mathrm{obs}}-Y_{i, \mathrm{mod}}\right) / Y_{i, \mathrm{obs}}\right|, \%$

HA - Monocarboxylic acid

$\overline{(\mathrm{HA})_{p}\left(\mathrm{NR}_{3}\right)_{q}}$ - Acid-amine complex

$\overline{(\mathrm{HA})_{p}\left(\mathrm{NR}_{2} \mathrm{H}\right)_{q}}$ - Acid-amine complex

$K_{a} \quad-$ Dissociation constant of acid

$N \quad$ - Number of observation

$\mathrm{NR}_{3}, \mathrm{NR}_{2} \mathrm{H} \quad-$ Tertiary and secondary amines
$P \quad-$ Pressure, $\mathrm{kPa}$

$p, q \quad-$ Number of acid and extractant molecules involved in the complex

$R \quad-$ Separation ratio optimization factor

$r, s \quad-$ Coefficients

$s_{\mathrm{f}}^{\text {chem }}, s_{\mathrm{f}}^{\text {phys }}-$ Chemical and physical separation factors of solvent mixture

$S E \quad-$ Synergistic enhancement factor

$T \quad-$ Temperature, $\mathrm{K}$

$v \quad-$ Volume fraction of diluent in solvent mixture

$x_{\mathrm{iv}} \quad-$ Independent variable

$Y \quad-$ Independent variable

$Z_{\mathrm{s}} \quad-$ Stoichiometric loading factor

$Z_{\mathrm{t}} \quad-$ Overall loading factor of extractant

$z \quad-$ Associated number

$(\overline{\text { overbar }})$ - Species in organic phase

\section{Greek letters}

$\beta_{\mathrm{L}}-$ Langmuir extraction constant, $(\mathrm{mol} \mathrm{dm})^{-3}$

$\beta_{p q} \quad-$ Apparent equilibrium extraction constant, $\left.(\mathrm{mol} \mathrm{dm})^{-3}\right)^{1-p-q}$

$\sigma \quad-$ Root-mean-square deviation, $\sigma=\left[\sum_{i=1}^{N}\left(Y_{i, \mathrm{obs}}-Y_{i, \mathrm{mod}}\right)^{2} / N\right]^{0.5}$

Subscripts

mod - Modeled

obs - Observed

\section{References}

1. Kertes, A. S., King, C. J., Extraction chemistry of fermentation product carboxylic acids, Biotechnol. Bioeng. 28 (1986) 269.

doi: http://dx.doi.org/10.1002/bit.260280217

2. Tamada, J. A., Kertes, A. S., King, C. J., Extraction of carboxylic acids with amine extractants. 1. Equilibria and law of mass action modeling, Ind. Eng. Chem. Res. 29 (1990) 1319.

doi: http://dx.doi.org/10.1021/ie00103a035

3. Tamada, J. A., King, C. J., Extraction of carboxylic acids with amine extractants. 2. Chemical interaction and interpretation of data, Ind. Eng. Chem. Res. 29 (1990) 1327. http://dx.doi.org/10.1021/ie00103a036

4. Yang, S. T., White, S. A., Hsu, S. T., Extraction of carboxylic acids with tertiary and quaternary amines: Effect of $\mathrm{pH}$, Ind. Eng. Chem. Res. 30 (1991) 1335.

doi: http://dx.doi.org/10.1021/ie00054a040

5. Bízek, V., Horácek, J., Koušová, M., Amine extraction of citric acid: Effect of diluent, Chem. Eng. Sci. 48 (1993) 1447.

doi: http://dx.doi.org/10.1016/0009-2509(93)80051-Q 
6. Poposka, F. A., Nikolovski, K., Tomovska, R., Equilibrium and mathematical models of extraction of citric acid with isodecanol $/ n$-paraffins solutions of trioctylamine, J. Chem. Eng. Japan 30 (1997) 777. doi: http://dx.doi.org/10.1252/jcej.30.777

7. Senol, A., Extraction equilibria of formic, levulinic and acetic acids using (Alamine 336/diluent) and conventional solvent systems: Modeling considerations, J. Chem. Eng. Japan 32 (1999) 717.

doi: http://dx.doi.org/10.1252/jcej.32.717

8. Senol, A., Effect of diluent on amine extraction of acetic acid: Modeling considerations, Ind. Eng. Chem. Res. 43 (2004) 6496.

doi: http://dx.doi.org/10.1021/ie0400954

9. Senol, A., Extraction equilibria of nicotinic acid using Alamine 336 and conventional solvents: effect of diluent, Chem. Eng. J. 83 (2001) 155. doi: http://dx.doi.org/10.1016/S1385-8947(00)00236-9

10. Senol, A., Influence of conventional diluents on amine extraction of picolinic acid, Sep. Purif. Technol. 43 (2005) 49. doi: http://dx.doi.org/10.1016/j.seppur.2004.09.013

11. Senol, A., Dramur, U., Predicting liquid-liquid equilibria of amine extraction of carboxylic acid through solvation energy relation, Solv. Extr. Ion Exch. 22 (2004) 865. doi: http://dx.doi.org/10.1081/SEI-200030286

12. Senol, A., Extraction equilibria of formic and levulinic acids using Alamine 308/diluent and conventional solvent systems, Sep. Purif. Technol. 21 (2000) 165. doi: http://dx.doi.org/10.1016/S1383-5866(00)00200-8

13. Senol, A., Influence of diluent on amine extraction of pyruvic acid using Alamine system, Chem. Eng. Process. 45 (2006) 755. doi: http://dx.doi.org/10.1016/j.cep.2006.03.002

14. Senol, A., Lalikoglu, M., Bilgin, M., Modeling extraction equilibria of butyric acid distributed between water and tri$n$-butyl amine/diluent or tri- $n$-butyl phosphate/diluent system: Extension of the LSER approach, Fluid Phase Equilib. 385 (2015) 153

doi: http://dx.doi.org/10.1016/j.fluid.2014.10.043

15. Heyberger, A., Procházka, J., Volaufova, E., Extraction of citric acid with tertiary amines - third phase formation, Chem. Eng. Sci. 53 (1998) 515. doi: http://dx.doi.org/10.1016/S0009-2509(97)00321-7

16. Malmary, G., Faizal, M., Albet, J., Molinier, J., Liquid-liquid equilibria of acetic, formic, and oxalic acids between water and tributyl phosphate + dodecane, J. Chem. Eng. Data 42 (1997) 985. doi: http://dx.doi.org/10.1021/je9700939

17. Ricker, N. L., Michaels, J. N., King, C. J., Solvent properties of organic bases for extraction of acetic acid from water, J. Sep. Proc. Technol. 1 (1979) 36.

18. Juang, R. S., Huang, W. T., Equilibrium studies on the extraction of citric acid from aqueous solutions with tri- $n$-octylamine, J. Chem. Eng. Japan 27 (1994) 498. doi: http://dx.doi.org/10.1252/jcej.27.498
19. Luque, S., Alvarez, J. R., Pazos, C., Coca, J., Recovery of valeric acid from aqueous solutions by solvent extraction, Solv. Extr. Ion Exch. 13 (1995) 923. doi: http://dx.doi.org/10.1080/07366299508918310

20. Senol, A., Extraction equilibria of valeric acid using (Alamine 336/diluent) and conventional solvent systems. Modeling considerations, Chem. Eng. Process. 41 (2002) 681. doi: http://dx.doi.org/10.1016/S0255-2701(01)00188-X

21. Kirsch, T., Maurer, G., Distribution of oxalic acid between water and organic solutions of tri- $n$-octylamine, Ind. Eng. Chem. Res. 35 (1996) 1722. doi: http://dx.doi.org/10.1021/ie9505827

22. Kamlet, M. J., Doherty, R. M., Abraham, M. H., Marcus, Y., Taft, $R$. W., Linear solvation energy relationships. 46. An improved equation for correlation and prediction of octanol/water partition coefficients of organic nonelectrolytes (including strong hydrogen bond donor solutes), J. Phys. Chem. 92 (1988) 5244. doi: http://dx.doi.org/10.1021/j100329a035

23. Marcus, Y., Linear solvation energy relationships. Correlation and prediction of the distribution of organic solutes between water and immiscible organic solvents, J. Phys. Chem. 95 (1991) 8886. doi: http://dx.doi.org/10.1021/j100175a086

24. Dean, J. A., Lange's Handbook of Chemistry, 30th ed., McGraw-Hill, New York, 1985.

25. Bauer, U., Marr, R., Ruckl, W., Siebenhofer, M., Reactive extraction of citric acid from aqueous fermentation broth, Ber. Bunsen-Ges. Phys. Chem. 93 (1989) 980. doi: http://dx.doi.org/10.1002/bbpc.19890930911

26. Baslioglu, B., Investigation of the Separation of Carboxylic Acids from the Aqueous Solutions by Using Liquid Membrane Technique, Ph.D. Thesis (in Turkish), Istanbul University, Institute of Science and Technology, 2012.

27. Senol, A., Optimum extraction equilibria of the systems (water + carboxylic acid + 1-hexanol/Alamine): Thermodynamic modeling, Fluid Phase Equilib. 360 (2013) 77. doi: http://dx.doi.org/10.1016/j.fluid.2013.09.012

28. Senol, A., Liquid-liquid equilibria for mixtures of (water + pyruvic acid + alcohol/Alamine): Modeling and optimization of extraction, J. Chem. Eng. Data 58 (2013) 528. doi: http://dx.doi.org/10.1021/je3012265

29. Senol, A., Optimal extractive separation of chromium(VI) from acidic chloride and nitrate media by commercial amines: Equilibrium modeling through linear solvation energy relation, Ind. Eng. Chem. Res. 52 (2013) 16321. doi: http://dx.doi.org/10.1021/ie4014309

30. Chang, Y.-L., Sullivan, R. S., Quantitative Systems for Business Plus (QSB+) V 2.0, Prentice-Hall Inc., Englewood Cliffs, New Jersey, 1991.

31. Himmelblau, D. M., Riggs, J., Basic Principles and Calculations in Chemical Engineering, eighth ed., Prentice-Hall Inc., Englewood Cliffs, New Jersey, 2012. 